\title{
Regulating electronic cigarettes: finding the balance between precaution and harm reduction
}

\author{
Ronald Labonté PhD, Raphael Lencucha PhD
}

CMAJ Podcasts: author interview at soundcloud.com/cmajpodcasts/regulating-ecig

Competing interests:

None declared.

This article has been peer reviewed.

Correspondence to:

Ronald Labonté

rlabonte@uottawa.ca

CMAJ 2015. DOI:10.1503 /cmaj.150347
I n March 2015, the federal Standing Committee on Health presented a report to the House of Commons on the highly contentious issue of how to regulate electronic nicotine delivery systems (ENDS), also called electronic cigarettes or e-cigarettes. After considering regulatory models that have been adopted elsewhere, which treat ENDS as therapeutic, tobacco or consumer products, the report concludes that ENDS require a "new legislative framework (under the Tobacco Act, new legislation, or other relevant statutes)."1 Almost all expert witnesses who presented to the committee agreed that ENDS are unique products distinct from tobacco products, but inappropriate for classification as a prescription drug. The report puts forward 14 recommendations, which represent a starting point for much needed dialogue about how best to fill the current federal regulatory gap with a clear strategy. Its recommendations include the need to disclose ingredients and to establish maximum nicotine levels, age restrictions for sale (18 yr), public consumption restrictions and flavouring prohibitions.

Canada currently bans the sale of e-cigarettes that contain nicotine, but enforcement has been patchy. There is uncertainty about health implications and what e-cigarettes might mean for the decades-long tobacco control movement. As ever with novel devices that are both popular and profitable, differences in what to do and when to do it revolve around questions of evidence. The federal government is being pressed to establish

\section{KEY POINTS}

- Canada is facing the challenge of how to regulate electronic cigarettes.

- Given the unknown risks associated with ENDS, as a precaution, measures similar to those for tobacco control should be implemented.

- To ensure the potential of ENDS as a harm-reduction tool, price measures should be used to encourage tobacco users to shift to e-cigarettes.

- For dependent smokers who are unable to quit and for whom affordability could be a barrier to shifting from tobacco to ENDS use, investigate supplying free or subsidized ENDS products. a comprehensive and evidence-based response to the rapid rise in ENDS use. ${ }^{2}$ Unfortunately, much of this evidence is emerging only now.

We briefly review the evidence as it pertains to four key questions at the heart of the ENDS debate before adding three reflections on a possible regulatory approach.

First, do ENDS represent an invitation to non-tobacco users to initiate uptake of these novel products? Durmowicz ${ }^{3}$ reviewed 14 studies published between 2011 and 2014 that examined consumption patterns among children and youth. Although varied, the findings suggest that never-smokers are less likely than former or current smokers to have tried ENDS. A Canadian study ${ }^{4}$ found that among the $16.7 \%$ of 1188 youth who reported ever trying ENDS, $5.2 \%$ were nonsmokers. Of the $5.7 \%$ who reported using ENDS in the past 30 days, only $0.8 \%$ were nonsmokers, a similar finding to a study conducted in Wales. ${ }^{5}$ Although ENDS uptake appears to remain low among nonsmokers, most of the research has been cross-sectional and may not capture a trajectory of uptake as e-cigarettes become more visible. Durmowicz notes: "The extent to which experimentation with e-cigarettes in youth will result in nicotine dependence and subsequent use of other tobacco products is unknown." 3

Second, do ENDS risk "renormalizing" conventional tobacco consumption? This question is the most complicated to answer with evidence. The ultimate marker would be whether tobacco consumption increases with the introduction of these novel nicotine devices. Because evidence to this effect would require a longitudinal analysis, many have argued that there is an urgent need to quash the current unrestricted freedom of the ENDS industry to promote their products; that is, we must regulate promotion of these products until we are able to measure and understand their potential harms. ${ }^{6}$

Third, what are the direct health risks to ENDS consumers and indirect risks to the wider 
public through second-hand exposure? Studies have shown that consumers perceive ENDS as less harmful than tobacco products. ${ }^{7}$ Evidence of the relative (compared with tobacco products) and absolute risk, however, is inconclusive. A systematic review from $2014^{8}$ cites early evidence that common carcinogenic elements found in tobacco products, such as nitrosamines, are found at much lower levels in e-cigarettes. ${ }^{8}$ However, the authors concluded that "due to the many methodological problems, the relatively few and often small studies, the inconsistencies and contradictions in results and the lack of long-term results, no firm conclusions can be drawn on the safety of [electronic cigarette]s." ${ }^{\circ}$

Fourth, are consumers of ENDS exposed to higher levels of nicotine, and if so, what are the health implications? Two separate studies found that nicotine levels varied greatly among different products $(2-15 \mathrm{mg}$ and $0.5-15.4 \mathrm{mg}$ per 300 puffs). ${ }^{9,10}$ Perhaps more importantly, nicotine levels in vapour did not correlate with nicotine levels printed on product packaging. Few other studies have examined nicotine levels in ENDS. Moreover, some studies are beginning to show that ENDS may serve as an important smoking cessation tool. ${ }^{11,12}$ If shown to be less harmful than traditional tobacco products, e-cigarettes could be a potential substitute for tobacco consumption.

Our brief overview of the state of the evidence underscores the uncertainty still surrounding ENDS. Their potential for health harm coupled with their paradoxical potential for harm reduction points to the need to approach ENDS regulation with nuance. This nuance should embody a regulatory approach aimed at preventing uptake by new nicotine users (i.e., never-smokers), while instituting inducements for cigarette smokers to shift to e-cigarettes as a harm-reduction and potential smoking-cessation tool.

It is encouraging that the federal government appears willing to act in the absence of scientific certainty. The prerogative to act under conditions of uncertainty, the so-called precautionary principle, is embedded in Canada's legislative framework: It is better to act on a reasoned assumption of substantial potential risk than to wait until the risk is real and widespread. The precautionary principle, which has long been a premise in United Nations standards regarding the environment, also reverses the burden of evidence to the producers.

What, then, might a nuanced regulatory approach to ENDS look like?

First, in regulating ENDS, we should draw from the many lessons learned regulating tobacco products, in terms of where they are sold, who can buy them, where they can be used and how they are promoted. Advertising, sponsorship and promotion bans, coupled with age restrictions and other common tobacco-control measures, will protect against renormalization and uptake by new users. This approach could be implemented rapidly by simply extending existing regulation to a new product until a new regulatory framework is established.

Second, to move toward a harm-reduction/ cessation strategy that embodies the public health mantra of "making health(ier) choices the eas(ier) choices," tax measures compliant with existing trade rules could ensure a price differential between ENDS and tobacco products. ${ }^{13}$ Such a price differential could encourage current smokers to "trade down" to a potentially less harmful product. Early studies suggest that ENDS are at least as effective as traditional nicotine replacement therapies as a cessation tool. ${ }^{3}$

Third, studies suggest that there is a small percentage of "hardcore" smokers who, no matter what they try, find it difficult or impossible to quit. For some people in this group (such as those in shelters, on social assistance or in other income support programs), the cost of ENDS may be a barrier. We can envision a preregulatory trial in which this group of smokers who cannot afford ENDS would be provided with e-cigarettes through a prescription or pharmacist consult, in much the same way that they may now be eligible for other nicotine replacement therapies.

Provinces like Ontario have begun to develop comprehensive legislation to control the promotion and use of ENDS. Bill 45, currently under review in Ontario, ${ }^{14}$ proposes to control ENDS much the same way as tobacco, implementing public consumption and advertising bans, among other measures. This precautionary approach is commendable, but must remain responsive to the harm-reduction potential of ENDS products.

In summary, and while not arguing that these are the only options, we propose that the regulatory way forward could consist of three simple steps. For the population as a whole, implement similar measures as those used for tobacco control. Use price measures to promote harm reduction by shifting tobacco use to ENDS use. For harm reduction among dependent smokers on social assistance programs, living in shelters or otherwise for whom ENDS affordability may still be a barrier to shifting from cigarette use, trial a free or subsidized supply of e-cigarettes and, if successful, generalize.

\section{References}

1. Vaping: towards a regulatory framework for e-cigarettes. Ottawa: Standing Committee on Health; 2015. Available: www. nsra-adnf.ca/cms/file/files/412_HESA_Rpt09-e.pdf (accessed 2015 Mar. 23). 
2. Oboum E. E-cigarette use slapped with growing provincial regulation [Internet]. Available: www.cbc.ca/1.2879168 (accessed 2015 Mar. 23).

3. Durmowicz EL. The impact of electronic cigarettes on the paediatric population. Tob Control 2014;23 Suppl 2:ii41-6.

4. Czoli CD, Hammond D, White CM. Electronic cigarettes in Canada: prevalence of use and perceptions among youth and young adults. Can J Public Health 2014;105:e97-102.

5. Moore G, Hewitt G, Evans J, et al. Electronic-cigarette use among young people in Wales: evidence from two crosssectional surveys. BMJ Open 2015;5:e007072.

6. Fairchild AL, Bayer R, Colgrove J. The renormalization of smoking? E-cigarettes and the tobacco "endgame." N Engl J Med 2014;370:293-5.

7. Adkison SE, O'Connor RJ, Bansal-Travers M, et al. Electronic nicotine delivery systems: international tobacco control fourcountry survey. Am J Prev Med 2013;44:207-15.

8. Pisinger C, Døssing M. A systematic review of health effects of electronic cigarettes. Prev Med 2014;69:248-60.

9. Goniewicz ML, Kuma T, Gawron M, et al. Nicotine levels in electronic cigarettes. Nicotine Tob Res 2013;15:158-66.

10. Goniewicz ML, Hajek P, McRobbie H. Nicotine content of electronic cigarettes, its release in vapour and its consistency across batches: regulatory implications. Addiction 2014;109:500-7.

11. Cahn Z, Siegel M. Electronic cigarettes as a harm reduction strategy for tobacco control: A step forward or a repeat of past mistakes? J Public Health Policy 2011;32:16-31.
12. Bullen $\mathrm{C}$, Howe $\mathrm{C}$, Laugesen $\mathrm{M}$, et al. Electronic cigarettes for smoking cessation: a randomised controlled trial. Lancet 2013;382: 1629-37.

13. Chaloupka FJ, Yurekli A, Fong GT. Tobacco taxes as a tobacco control strategy. Tob Control 2012;21:172-80.

14. Bill 45, Making Healthier Choices Act, 2015. An Act to enhance public health by enacting the Healthy Menu Choices Act, 2014 and the Electronic Cigarettes Act, 2014 and by amending the Smoke-Free Ontario Act, 1st Sess, 41st Parl, Ontario, 2015.

Affiliations: Globalization and Health Equity (Labonté), Institute of Population Health, and the School of Epidemiology, Public Health and Preventive Medicine, University of Ottawa, Ottawa, Ont.; Faculty of Medicine (Lencucha), School of Physical and Occupational Therapy, McGill University, Montréal, Que.

Contributors: The authors developed the commentary collaboratively. Ronald Labonté wrote a first draft, which Raphael Lencucha revised. Both authors approved the version to be published and agree to act as guarantors of the work.

Funding: Ronald Labonté receives funding as Canada Research Chair of Globalization and Health Equity. 